Laser Chem. 1988, Vol. 8, pp. 303-313

(C) 1988 Harwood Academic Publishers GmbH

Photocopying permitted by license only

Reprints available directly from the Publisher

Printed in the United Kingdom

\title{
Laser Induced Synthesis: Condensation of Acrylonitrile on Carvone
}

\author{
R. STRINGAT† and F. LEMAIRE
}

Laboratoire d'Optique Atomique et Moléculaire

R. FELLOUS and A. M. LOISEAU

Laboratoire de Chimie des Arômes

Université de Nice, Parc Valrose 06034 Nice Cedex France

Laser irradiation of $\mathrm{R}(-)$ carvone in solution in acrylonitrile within the absorption band of its $n-\pi^{*}$ transition $(\simeq 350 \mathrm{~nm})$ leads to the formation of cyclobutanic adducts, together with traces of camphocarvone.

The carvone transformation is complete and appears with high quantum efficiency. The quantum yield for intermolecular reaction is intensity dependent $(13-30 \%)$. This is ascribed to the fact that the reaction takes place via both a one and a two-photon absorption channel, the second being even more efficient.

KEY WORDS: Laser; photochemistry; multiphoton; organic synthesis; cyclobutanes; terpenes.

\section{INTRODUCTION}

Some terpenic compounds with a nitrile function are described in the literature as "green note" derivatives. ${ }^{1}$ Their potential interest is thus considerable and has led us to investigate an example of synthesis starting from $\mathbf{R}(-)$ carvone (1) (used on large scale in the flavoring industry) and acrylonitrile (2). 

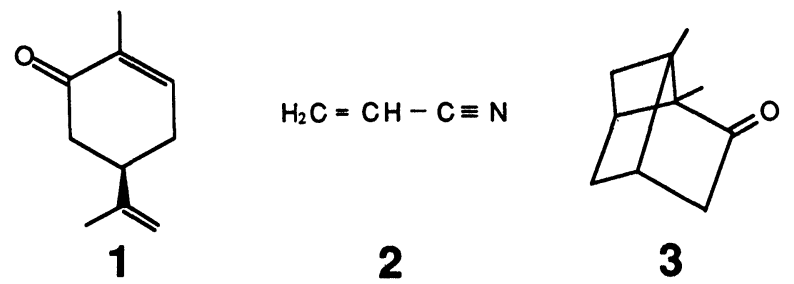

Photochemistry allows addition of functionalised alkenes on cyclic enones. Examples of such photoadditions were studied, particularly on cyclohexenones and methylcyclohexenones, about twenty years ago. ${ }^{2,3}$ It must be pointed out, however, that broad-band light sources generally used in photochemistry result in the parasite polymerisation of acrylonitrile and hence opacification of the solution. Selective excitation of the enone must therefore be used. For this purpose, the laser is a tool of choice due to its high spectral purity. This clearly emerges from our previous work on mesityl oxide. ${ }^{4}$ Moreover, in that case, an important growth of the quantum yield of the addition with acrylonitrile was obtained on increasing the intensity. This shows the possible advantage of using high intensity sources. Lastly, the spatial coherence of the laser results in easy photon-to-reagent coupling. An additional advantage is that significant quantum yield values can be more easily calculated (due to the good knowledge of the incident photon number).

All these positive factors encouraged us to investigate the condensation of acrylonitrile on $\mathrm{R}(-)$ carvone with laser irradiation at wavelengths close to $350 \mathrm{~nm}$, corresponding to the $n-\pi^{*}$ transition $\left(\varepsilon_{350} \simeq 151 / \mathrm{mol} . \mathrm{cm}, \lambda \max \left(n \rightarrow \pi^{*}\right)=318 \mathrm{~nm}(42), \lambda \max \left(\pi \rightarrow \pi^{*}\right)=\right.$ $235 \mathrm{~nm}(8511))$. By contrast, acrylonitrile does not absorb at this wavelength (measured $\varepsilon_{350}$ value $\simeq 0, \lambda \max =203 \mathrm{~nm}(6166)$.

\section{EXPERIMENTAL CONDITIONS}

Initially, the beam was directed to the top of an open cooled cell, or horizontally through a fused silica cell containing a few millilitres of the solution. This volume was fully sufficient to obtain photoproducts in suitable quantities for chromatographic analysis in reasonable irradiation times (10-30 mn). Concentration of the solution was optimised 
to $0.3 \mathrm{M}$ (carvone in acrylonitrile), the highest yields being obtained for this value.

Three light sources were employed so as to vary the intensity over a wide range using either neutral filters or more or less sharp focusing of the beam. The characteristics of the light sources are as follows:

-High-pressure mercury lamp (150 W);

-C.W. Argon laser at 351,1 nm;

-Frequency tripled pulsed Nd-YAG at $355 \mathrm{~nm}$ (pulse energy: $45 \mathrm{~mJ}$ max, duration: $13 \mathrm{~ns}$, repetition rate: $10 \mathrm{~Hz}$ ).

Energy measurements were made with a Scientech 362 calorimeter.

\section{EXPERIMENTAL RESULTS}

As expected, irradiation with an unfiltered high-pressure mercury lamp resulted in rapid acrylonitrile polymerisation opacifying the solution. By contrast, no polymerisation was detected following laser irradiation. The spectral width of the mercury lamp could clearly be reduced by using adequate filters so as to suppress the acrylonitrile polymerisation. However it would not be possible, with this source, to reach the intensity values necessary to observe the phenomena described below.

Capillary Gas Phase Chromatography of the laser-irradiated mixtures revealed seven supplementary products as well as traces of camphocarvone (3). The three major products $(58 \%, 26 \%, 8 \%)$ were isolated. Their relative proportions were constant in all experimental conditions.

Technical procedure and analytical data are summarised below:

-A dynamic flow system including a Suprasil cylindrical cell and a geared micropump (S\&T 040332) were used for quantitative production $(\approx 200 \mathrm{mg} / \mathrm{h})$.

-Ethylene glycol was used as internal standard for quantitative analysis of chromatograms.

-Separation of products was done in several steps:

5 and 6 were obtained by preparative GPC (AEROGRAPH AUTOPREP A700) using a CARBOWAX $20 \mathrm{M}$ column $(3 \mathrm{~m} / 1 \mathrm{~cm}, 20 \%) .5$ is a yellow viscous liquid and 6 is a colorless solid (recrystallised in acetone). 
The fraction including 4 was obtained by preparative GPC and 4 was then isolated using preparative TLC plates (MACHEREYNAGEL $1 \mathrm{~mm}$ SIL G100; ternary eluting mixture: HEXANE/ $\left.\mathrm{HCCl}_{3} / \mathrm{MeOH} 68 / 27 / 5\right) .4$ is a yellow viscous liquid.

-Spectroscopic data: The detection of photoproducts and their qualitative and quantitative analysis were carried out by capillary GPC, GC/MS coupling, IRFT and NMR.

\section{Mass spectra}

4: $\mathrm{m} / \mathrm{z} 82(100 ; 39(69) ; 41(61.6) ; 95(51.7) ; 93(46) ; 94(44.6) ; 67(43)$; 79(34.9); 68(31.6); 80(29.4); 203(6.8).

5: $\mathrm{m} / \mathrm{z}$ 95(100); 82(46.7); 67(45.7); 39(45.5); 41(41.5); 68(33.1); 110(26); 94(21); 79(20.4); 93(19.5); 203(6.8).

6 has the same spectrum as 5 , apart from a few differences in intensity.

\section{IRFT}

4: $v(\mathrm{C}=0)=1711 \mathrm{~cm}^{-1} \quad v(\mathrm{CN})=2250 \mathrm{~cm}^{-1}$.

5: $v(\mathrm{C}=0)=1709 \mathrm{~cm}^{-1} \quad v(\mathrm{CN})=2243 \mathrm{~cm}^{-1}$.

6: $v(\mathrm{C}=0)=1703 \mathrm{~cm}^{-1} \quad v(\mathrm{CN})=2230 \mathrm{~cm}^{-1}$.

${ }^{13} \mathrm{C}$ NMR spectra were obtained at $22.6 \mathrm{MHz}$.

4: $\left(\mathrm{CDCl}_{3}\right) \delta=212 \mathrm{ppm}(\mathrm{C}=0) ; 146.7$ (=C $\left.\leq\right) ; 119.7(\mathrm{CN})$; $110.4\left(=\mathrm{CH}_{2}\right) ; 49(\mathrm{C}) ; 42.3\left(\mathrm{CH}_{2}\right) ; 40.7(2 \mathrm{XCH}) ; 33.5\left(\mathrm{CH}_{2}\right)$; $28.1(\mathrm{CH}) ; 28.1\left(\mathrm{CH}_{2}\right) ; 21.7\left(\mathrm{CH}_{3}\right) ; 20.2\left(\mathrm{CH}_{3}\right)$.

5: $\left(\mathrm{CDCl}_{3}\right) \delta=211.5 \mathrm{ppm}(\mathrm{C}=0) ; 146.7$ (=- $\left.\mathrm{C}^{\prime}\right) ; 120.4(\mathrm{CN})$; $110.7\left(=\mathrm{CH}_{2}\right) ; 49.8(\mathrm{C}) ; 44.2\left(\mathrm{CH}_{2}\right) ; 40.5(\mathrm{CH}) ; 40.3\left(\mathrm{CH}_{2}\right)$; $34.4(\mathrm{CH}) ; 30.6(\mathrm{CH}) ; 28.1\left(\mathrm{CH}_{2}\right) ; 25.1\left(\mathrm{CH}_{3}\right) ; 20.3\left(\mathrm{CH}_{3}\right)$.

6: $\left(\mathrm{CDCl}_{3}\right) \delta=211.4 \mathrm{ppm}(\mathrm{C}=0) ; 146.7(=\mathrm{C}) ; 119.3(\mathrm{CN})$; $110.6\left(=\mathrm{CH}_{2}\right) ; 51.8(\mathrm{C}) ; 44.3\left(\mathrm{CH}_{2}\right) ; 41.2(\mathrm{CH}) ; 39.3\left(\mathrm{CH}_{2}\right)$ $30.5(\mathrm{CH}) ; 29.9(\mathrm{CH}) ; 26.5\left(\mathrm{CH}_{2}\right) 24.5\left(\mathrm{CH}_{3}\right) ; 20.6\left(\mathrm{CH}_{3}\right)$.

' $\mathrm{H}$ NMR spectra were obtained at $80 \mathrm{MHz}$ and $200 \mathrm{MHz}$.

4: $\delta=4.65$ and $4.75 \mathrm{ppm}$ ( $2 \mathrm{H}$, vinylic protons); $3.4(\mathrm{q}, 1 \mathrm{H})$; from 1.96 to $2.67 \mathrm{ppm}$ (multiplet, $8 \mathrm{H}) ; 1.66\left(\mathrm{~s}, \mathrm{CH}_{3}\right) ; 1.45\left(\mathrm{~s}, \mathrm{CH}_{3}\right)$.

5: $\delta=4.72$ and $4.78 \mathrm{ppm}(2 \mathrm{H}$, vinylic protons); 2.91 (eight lines signal, 1H); 2.66 (multiplet, 3H); 2.39 (multiplet, 3H); 2.17 (multiplet, $1 \mathrm{H}) ; 1.92(\mathrm{td}, 1 \mathrm{H}) ; 1.71\left(\mathrm{~s}, \mathrm{CH}_{3}\right) ; 1.41\left(\mathrm{~s}, \mathrm{CH}_{3}\right)$. 
6: $\delta=4.68$ and $4.86 \mathrm{ppm}(2 \mathrm{H}$, vinylic protons); $2.83(\mathrm{t}, 1 \mathrm{H}) ; 2.16$ to 2.62 (multiplet, $7 \mathrm{H}) ; 2.03(\mathrm{q}, 1 \mathrm{H}) ; 1.74\left(\mathrm{~s}, \mathrm{CH}_{3}\right) ; 1.34\left(\mathrm{~s}, \mathrm{CH}_{3}\right)$.

These spectroscopic data revealed the formation of new compounds and point to structures 4,5 and 6 :

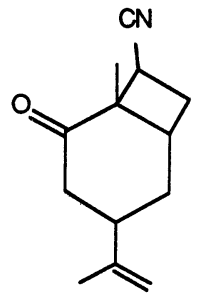

$(58 \%)$

4

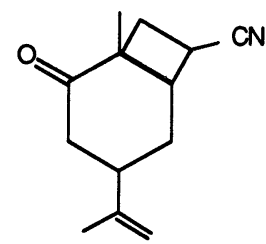

$(26 \%)$

5

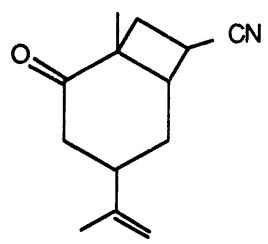

$(8 \%)$

6

Determination of the stereochemistry is under current investigation. Main features of UV spectra are: 4: $\lambda \max =258 \mathrm{~nm}(89), 5: \lambda \max =$ $251 \mathrm{~nm}(83), 6: \lambda \max =230 \mathrm{~nm}$ (726). Absorption coefficient $\varepsilon$ of compounds $4,5,6$ is of the same order than for carvone but these products are photostable at $355 \mathrm{~nm}$ since their mutual proportion is constant and the transformation of carvone is quantitative (except for traces of camphocarvone).

The quantum yield was defined as the ratio between the number of molecules of the photoproducts of interest and the number of photons necessary to produce them in conditions where the whole light flux is absorbed by the solution. Special care was taken in the determination of these two parameters. Gas phase chromatography was performed, using an internal standard, and corrected for the specific detector response to the photoproducts. Intensity of laser light was experimentally corrected for reflexion on the entrance window of the cell. It must be noted that, due to its transverse change across the beam, the measured intensity obviously has the meaning of an average spatial value.

The quantum yield $\Phi$ of the transformation in the cyclobutanic derivatives was calculated for each intensity, the irradiation time being limited to a value giving a conversion that never exceeded $30 \%$. It must be noted, however, that further irradiation results in the total transformation of carvone. The $\Phi=f(I)$ graph is presented in Figure 1. The 


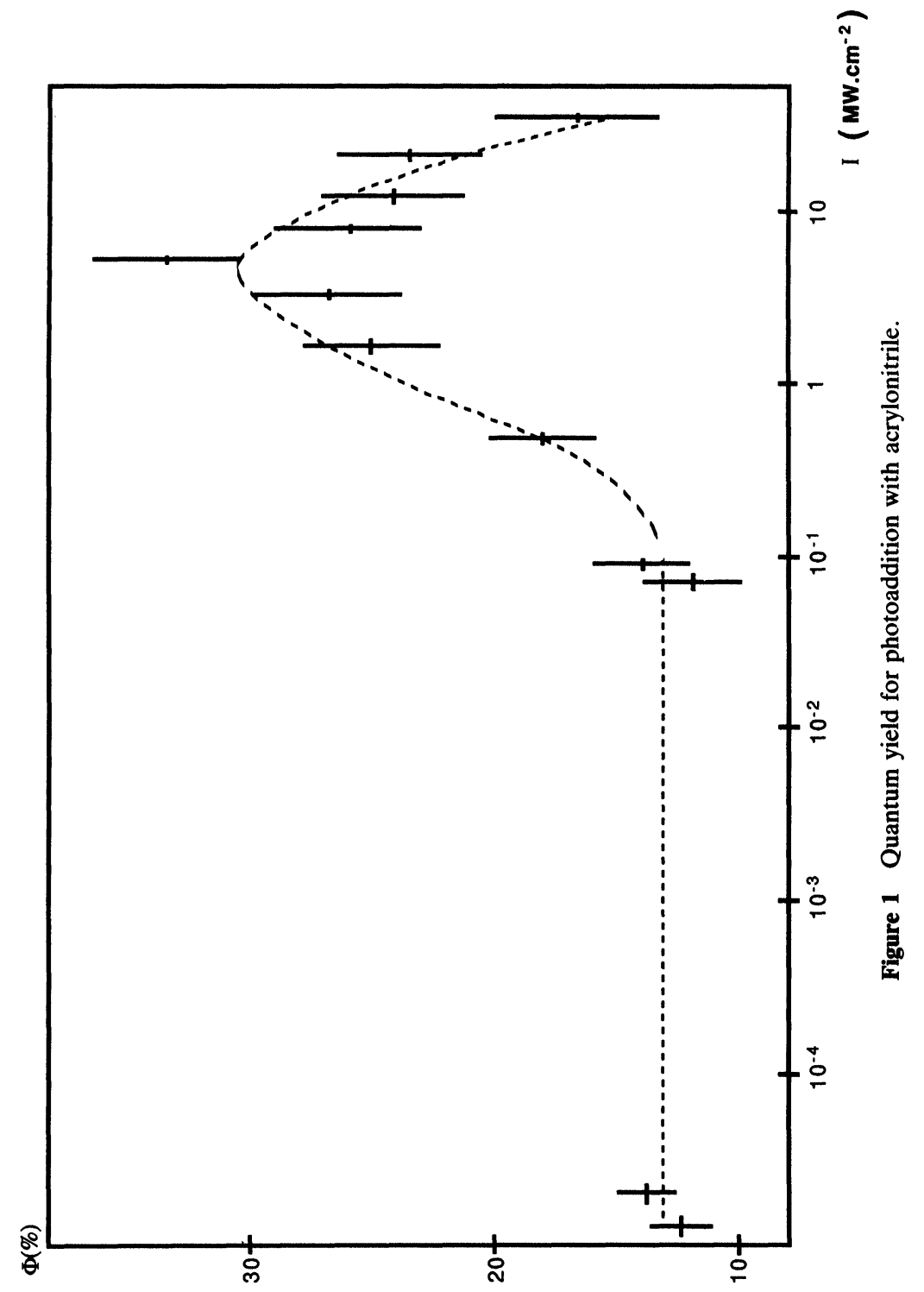


first two points are obtained with the $\mathrm{CW}$ laser, the others with the pulsed laser. The gap between the two series corresponds to a range not easily accessible.

A comparison was also made between high-majority intermolecular photocycloaddition products and camphocarvone (internal photocyclisation) at different intensities (see Figure 2).

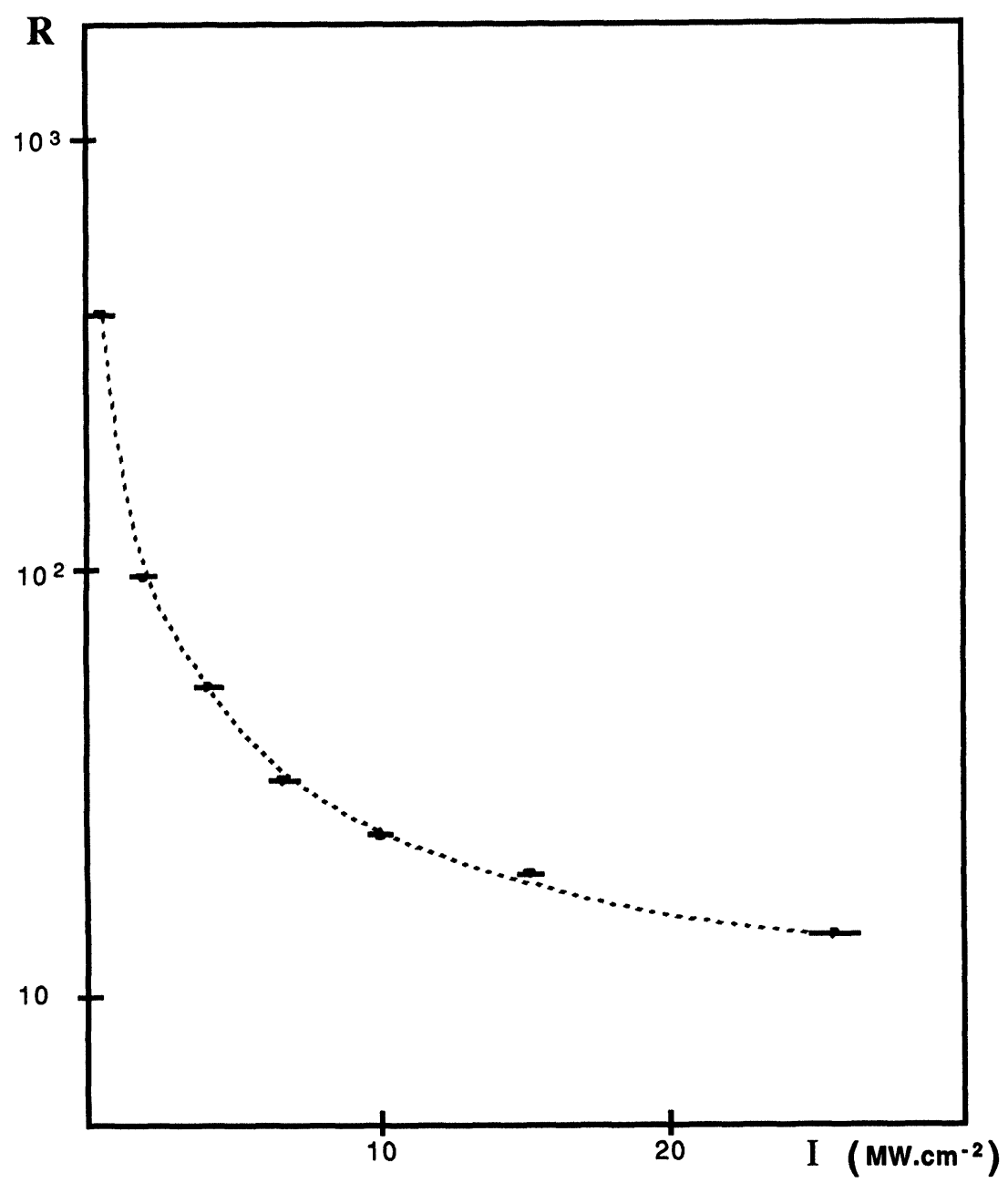

Figure 2 Ratio between acrylonitrile addition and camphocarvone formation quantum yields. 


\section{DISCUSSION}

The first point worthy of note is the very high quantum yield for the formation of cycloadducts: $13-30 \%$, i.e. well above the $0.3-7 \%$ previously observed for internal cyclisation only. ${ }^{5}$ Figure 2 shows that competition between the intra and intermolecular reaction is always clearly in favour of the latter, though less markedly at high intensity.

Moreover, the variation of the yield in function of intensity (Figure 1) indicates that several excitation paths exist. These, however, all lead, more or less efficaciously, to the same addition products.

The first part of the curve, in fact, shows that the yield does not initially depend on the intensity, which varies over a wide range whose extremes are in the ratio of 1 to 10,000 . At low intensity, the absorption process may involve a single photon only. Observations with the mercury lamp confirm the possibility of the monophotonic route: traces of addition products are obtained before complete opacification of the solution by the acrylonitrile polymer. However, we have no information to conclude whether singlet $S_{1}$ or triplet $T_{1}$ (or both) is involved in the chemical reaction.

The second part of the curve $\left(0.1 \leqq I \leqq 6.4 \mathrm{MW} / \mathrm{cm}^{2}\right)$ shows a dependence of $\Phi$ on intensity. This can be explained by absorption of a second photon by some of the excited molecules. The variation observed is an increase. This indicates that the new excited species is even more reactive, leading to the same products.

Quantitative interpretation of the curve (Figure 1) is very delicate and beyond the scope of this work. However, the following considerations indicate which is the most probable mechanism and permit comparison between chemical reactivity and spontaneous decay for the doubly excited carvone molecule. Due to the spatial-mode quality of the beam and the decrease of intensity across the reaction cell together with probable self-focusing or defocusing effects, the part played by each of the two processes at each point changes, and the quantum yield calculated then takes an average spatial value. At low intensity points, the local quantum yield must have the $13 \%$ value corresponding to the one-photon route. For medium intensity points, the one-photon and the two-photon processes appear together. Lastly, if intensity is sufficient in some parts of the cell, the one-photon process will be completely eliminated or not, according to which of the following mechanisms is involved. If the absorption of a second photon 
comes from $S_{1}$ (Figure 3 case 1), the previous chemical reaction disappears (irrespective of whether it comes from $S_{1}$ or $T_{1}$ ) and the theoretical limit for the quantum yield $\Phi$ for all the photochemical reactions is then 0.5 . If the second absorption takes place starting from $T_{1}$, two possibilities must be considered. In the first (Figure 3 case b), the excited state reacting chemically is $T_{1}$ : the one-photon reaction disappears and the limit yield is $\rho /(1+\rho)<0.5$ (where $\rho$ is the quantum yield for the intersystem transition). In the second (Figure 3 case c), $S^{1}$ intervenes in the photochemical reaction with quantum yield 0.13 . This process persists and the limit of the quantum yield of both reactions (from $S_{1}$ and $\left.T_{n}\right)$ is $(0.13+\rho) /(1+\rho)$, whose maximum value (corresponding to $\rho=1-0.13$ ) is 0.53 . In any of these three cases, the quantum yield will be less than 0.53 .

Neither the radiative lifetimes for the $S_{1}$ and $T_{1}$ states, nor the probability of intercombination system transition are known for carvone. It follows that we have no quantitative possibility to choose between the singlet $\left(S_{1} \rightarrow S_{n}\right)$ and triplet $\left(T_{1} \rightarrow T_{n}\right)$ channels for the second absorption step. Nevertheless, the latter corresponds to the more probable path, in view of the required energy intervals evaluated by Letokhov ${ }^{6}$ for the absorption of a second photon $\left(10^{3}-10^{6} \mathrm{~W} / \mathrm{cm}^{2}\right.$ starting from $T_{1} ; 10^{9}-10^{10} \mathrm{~W} / \mathrm{cm}^{2}$ starting from $S_{1}$ ) in his review article on laser-induced chemistry.

For $I \geqq 0.1 \mathrm{MW} / \mathrm{cm}^{2}$, our experimental procedure (all the photons absorbed) leads to the presence of the one and the two-photon processes. It obviously implies that the measured average value of the quantum yield must be comprised between 13\% (actual value for the one photon process-the yield for internal cyclisation being negligible) and $53 \%$ (upper theoretical limit). The high average value obtained at $I=6.4 \mathrm{MW} / \mathrm{cm}^{2}(30 \%$ for intermolecular addition plus $1 \%$ for internal cyclisation) implies that the actual yield, in the spatial region where the two-photon process dominates, is very close to its theoretical limits indicating that the kinetic constant is much higher than the probability of spontaneous decay.

It should also be noted that internal cyclisation is distinctly more competitive at intensity values nearing the maximum of curve 1 . This is in keeping with Schafer's observation ${ }^{5}$ of a very large increase in internal cyclisation quantum yield with intensity.

Lastly, the third part of the curve, corresponding to the highest intensities, displays a decrease of the quantum yield. An unfavorable 


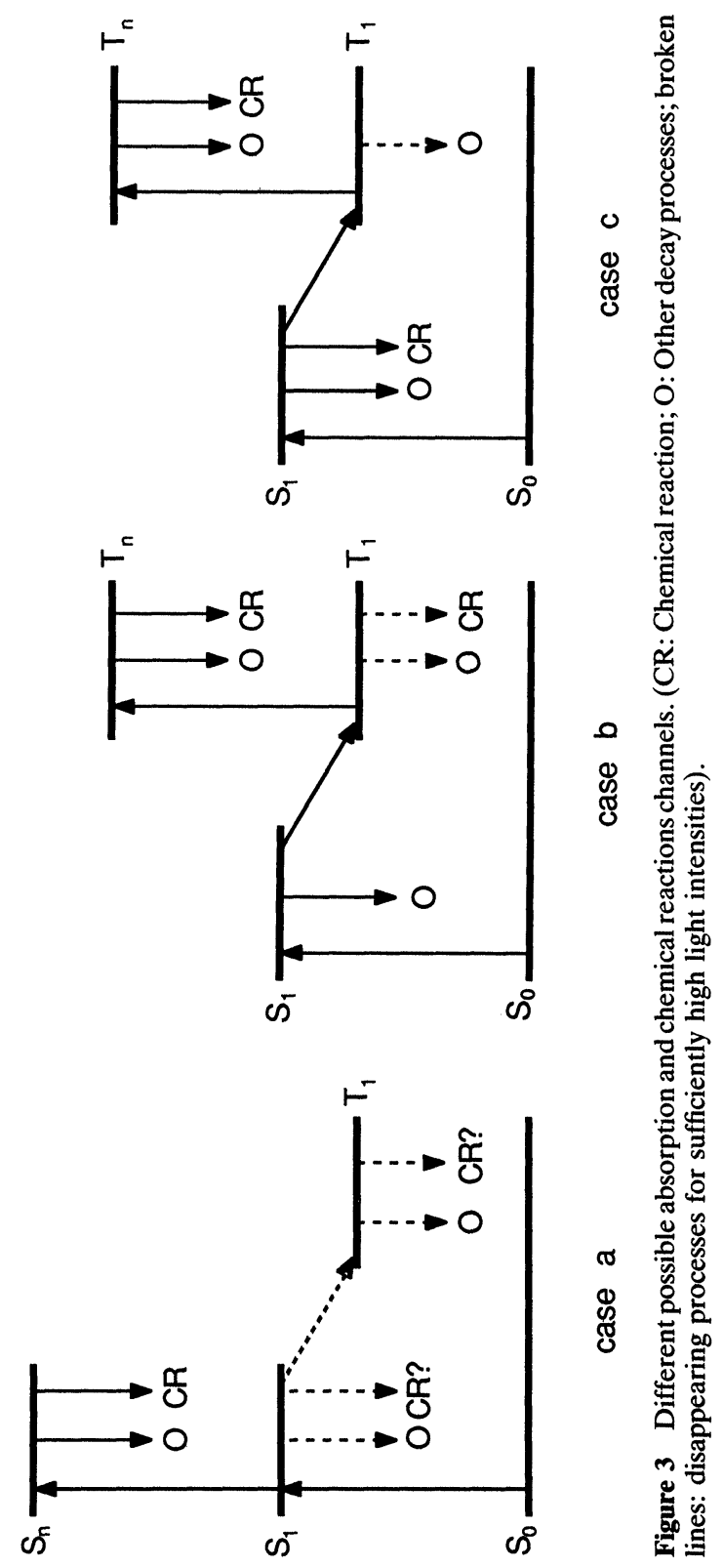


process intervenes at this point. It appears to affect both internal cyclisation and intermolecular addition, since their ratio tends to become constant. It should be noted that this decrease is not a drawback for synthesis applications. In effect, the only experimental change in the interval between $I=0.56 \mathrm{MW} / \mathrm{cm}^{2}$ and $I=45 \mathrm{MW} / \mathrm{cm}^{2}$ relates to the focusing of the beam. It is clear, of course, that the focusing giving the maximum $\Phi$ value will be chosen.

\section{CONCLUSION}

This work has shown the possibility of synthesis of cyclobutanic derivatives of the $R(-)$ carvone by means of UV laser photochemistry.

High quantum efficiency is a distinctive characteristic of the reaction. This stems from a one photon absorption process for $I \leqq 0.1$ $\mathrm{MW} / \mathrm{cm}^{2}$, to which is added a two-photon process of increasing weight for $0.1 \leqq I \leqq 6.4 \mathrm{MW} / \mathrm{cm}^{2}$.

The doubly excited molecule is more reactive and leads to the same products with a greater quantum yield, even though the theoretical limit is evidently less than that corresponding to a one-photon process.

This paper offers one of the very first examples of the potentiation of organic synthesis by two-photon photochemistry.

\section{Acknowledgement}

The authors are very grateful to Dr Michel Rouillard for his invaluable help in the NMR analysis.

\section{References}

1. D. Lamparsky, Parfumerie und Kosmetic, 1, 5 (1984).

2. T. S. Cantrell, W. S. Haller and J. C. Williams, J. Org. Chem. 34, 3 (1969).

3. W. G. Dauben, G. W. Schaffer and N. D. Vietmeyer, J. Org. Chem. 33, 11 (1968).

4. F. Lemaire, R. Stringat, C. Bertaina and R. Fellous, Tetrahedron Lett. 27, 46 (1986).

5. U. Brackmann and F. P. Schafer, Chem. Phys. Lett. 87, 579 (1982).

6. V. S. Letokhov, Nature, 305, 103 (1983). 